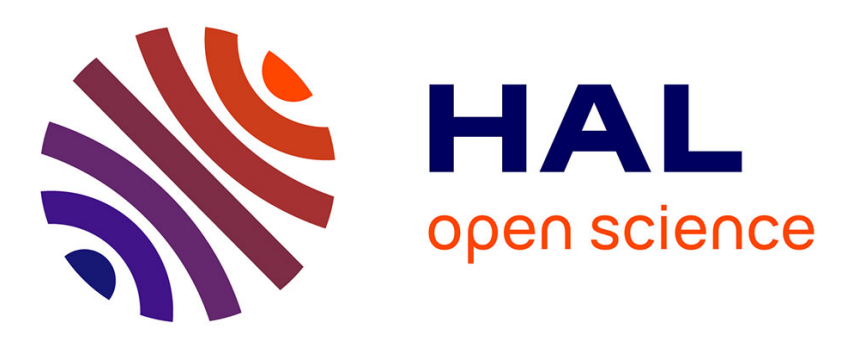

\title{
Evidence and modeling of mechanoluminescence in a transparent glass particulate composite
}

\author{
Marion Dubernet, Yann Gueguen, Patrick Houizot, Fabrice Célarié, \\ Jean-Christophe Sangleboeuf, Hervé Orain, Tanguy Rouxel
}

\section{- To cite this version:}

Marion Dubernet, Yann Gueguen, Patrick Houizot, Fabrice Célarié, Jean-Christophe Sangleboeuf, et al.. Evidence and modeling of mechanoluminescence in a transparent glass particulate composite. Applied Physics Letters, 2015, Applied Physics Letters, 107 (15), pp.151906. 10.1063/1.4933331 . hal-01219188

\author{
HAL Id: hal-01219188 \\ https://hal.science/hal-01219188
}

Submitted on 22 Oct 2015

HAL is a multi-disciplinary open access archive for the deposit and dissemination of scientific research documents, whether they are published or not. The documents may come from teaching and research institutions in France or abroad, or from public or private research centers.
L'archive ouverte pluridisciplinaire HAL, est destinée au dépôt et à la diffusion de documents scientifiques de niveau recherche, publiés ou non, émanant des établissements d'enseignement et de recherche français ou étrangers, des laboratoires publics ou privés. 


\title{
Evidence and modeling of mechanoluminescence in a transparent glass particulate composite
}

\author{
Marion Dubernet, ${ }^{1}$ a) Yann Gueguen, ${ }^{1}$ Patrick Houizot, ${ }^{1}$ Fabrice Célarié, ${ }^{1}$ \\ Jean-Christophe Sangleboeuf, ${ }^{1}$ Hervé Orain, ${ }^{1}$ and Tanguy Rouxel ${ }^{1, \text { a) }}$ \\ Département Mécanique et Verres, IPR, UMR UR1-CNRS 6251, \\ Université de Rennes 1, Campus de Beaulieu, 35042 Rennes Cedex, \\ France
}

Mechanoluminescence of a transparent alkali-phosphate glass composite with $\mathrm{SrAl}_{2} \mathrm{O}_{4}: \mathrm{Eu}$, Dy particles is reported. Uniaxial compression experiments show the linear dependence of the mechanoluminescence intensity with the mechanical power. A theoretical model, based on the physics of delayed processes (in analogy of viscoelasticity), is proposed. This model accurately predicts the ML intensity changes induced by a complex mechanical loading and provides a convincing description of the mechanoluminescence response.

a) Corresponding authors: marion.dubernet@univ-rennes1.fr; tanguy.rouxel@univ-rennes1.fr; Département Mécanique et Verres, IPR, UMR UR1-CNRS 6251 : www.ipr.univ-rennes1.fr/d6?mtop=dpt6\%C26lang=en/ 
Mechanoluminescence (ML) is the phenomenon of light emission generated by a mechanical loading. Elastico mechanoluminescence (EML), plastico mechanoluminescence (PML) and fracto mechanoluminescence (FML) are ML phenomena respectively induced by elastic deformation, plastic flow and fracture of solids. ML was already reported by Bacon ${ }^{1}$ 5 in the begining of $17^{\text {th }}$ century when he scratched lumps of sugar in the dark. Some aluminate based ceramic components are also well-known to be mechanoluminescent, among which $\mathrm{SrAl}_{2} \mathrm{O}_{4}$ :Eu, Dy (SAOED) exhibits very intense EML, PML and FML ${ }^{2}$. In the past 30 years, many reports were devoted to the EML of strontium aluminate particles codoped with Eu and Dy. The EML intensity was found to depend linearly on the applied stress making this material promising for stress sensor applications ${ }^{3}$. Moreover, the SAOED particles can be used to synthesize polymer composites in the form of thin films ${ }^{4}$, epoxy disks ${ }^{5}$, fibers ${ }^{6}$ and also paints ${ }^{7}$. Nevertheless, no attempt to elaborate a transparent SAOED particulate inorganic glass composite was reported so far.

In the present study, a transparent material consisting of an alkali-phosphate glass matrix and SAOED particles was elaborated by melt-quenching method. A phosphate glass with a low melting temperature has been chosen as a vitreous matrix to avoid denaturing (overheating) SAOED particles during the synthesis. $\mathrm{SrAl}_{2} \mathrm{O}_{4}: \mathrm{Eu}$, Dy particles were introduced in a glass with the following stoichiometric composition $0.25 \mathrm{Na}_{2} \mathrm{O}-0.50 \mathrm{P}_{2} \mathrm{O}_{5}-0.25 \mathrm{Li}_{2} \mathrm{O}$. An uniaxial loading experiment in compression revealed that the particles keep their ML properties after the synthesis of the composite at high temperature. The peculiarities of the ML phenomenon in such system were then explored by means of different mechanical loading cycles, and a model relating the light intensity to the mechanical power is proposed.

Composite materials with composition $(1-x)\left(0.25 \mathrm{Na}_{2} \mathrm{O}-0.50 \mathrm{P}_{2} \mathrm{O}_{5}-0.25 \mathrm{Li}_{2} \mathrm{O}\right), x$ $\mathrm{SrAl}_{2} \mathrm{O}_{4}: \mathrm{Eu}$, Dy with $x=0.03$, were synthesized by the melt-quenching method. $\mathrm{NaH}_{2} \mathrm{PO}_{4}$ (Aldrich, $\geq 99 \%$ ), $\mathrm{LiH}_{2} \mathrm{PO}_{4}$ (Aldrich, 99\%) and $\mathrm{SrAl}_{2} \mathrm{O}_{4}: \mathrm{Eu}$, Dy (Aldrich, 99\%) powders were mixed in a platinum crucible and were prefired until $300^{\circ} \mathrm{C}$ for $3 \mathrm{~h}$ to remove water from the powder mixture. Then the crucible was placed for 2 min into a furnace preheated at $800^{\circ} \mathrm{C}$. The glass was poured into a stainless steel mold which was preheated at $240{ }^{\circ} \mathrm{C}$, corresponding to the glass transition $\left(T_{g}\right)$ of the glassy matrix and further annealed at this temperature for $2 \mathrm{~h}$ to reduce the residual stresses. Composite batches were cut into rectangular samples with a diamond saw and polished to mirror surface finish $(0.5 \mu \mathrm{m}$ grade diamond suspension). 
Compression experiments were conducted on parallelepiped specimen ( 4 x 4 x $4.47 \mathrm{~mm}^{3}$ ) along its longest size, using an universal testing machine (LLoyd LR $50 \mathrm{~K}$ ). Specimens were (Fig.2). In the literature, the linear relationship was suggested between the ML intensity of $\mathrm{SrAl}_{2} \mathrm{O}_{4}: \mathrm{Eu}$, Dy and the applied pressure ${ }^{8}$ or the applied stress ${ }^{9}$. In an earlier study ${ }^{10}$, the ML intensity was proposed to scale with $\sigma \dot{\sigma}$ ( $\sigma$ : stress). In agreement with this latter 

mechanical power $(\mathrm{P})$ which, for a linear elastic body is given by:

$$
P=\sigma \dot{\sigma} / E
$$

where $E$ is Young's modulus, $\sigma$ the uniaxial stress $(E=53 \pm 1 \mathrm{GPa}$, as measured by ultrasonic wave velocities) and $\dot{\sigma}$ the time derivative of $\sigma$.

A potential application for EML materials is the development of stress sensors ${ }^{3}$. It is stress needs to be elucidated, especially for complex loading histories. Until now, the proposed relationships are limited to rather simple loading conditions (typically constant stress rate $)^{11,12}$. The model we proposed in this study intends to reproduce the following ML intensity changes observed in some materials, where the mechanisms of EML are similar to gral" is commonly used ${ }^{17}$. We assume first that the ML intensity $\left(I_{M L} \geq 0\right)$ is proportional to a function $f$ defined as: 


$$
f(t)=\left|\frac{d}{d t} \int_{0}^{t} \frac{\varphi(t-s)}{2 E} \frac{\partial \sigma^{2}(s)}{\partial s} d s\right|
$$

where $\varphi$ is a retardation function $(\dot{\varphi}(t) \geq 0, \varphi(t \leq 0)=0$ and $\varphi(t)=1$ when $t \rightarrow+\infty)$. Indeed, $f$ is simply proportional to the time derivative of the stored elastic energy $\left(\sigma^{2} / 2 E\right)$, tial distribution of traps with energy ${ }^{18}$ (in agreement with what is expected for a crystal). Consequently, the model has only 4 parameters: $\phi, \psi, \tau$ and $\beta$. According to the obtained equations, the model suggests that a fraction of the mechanical energy stored by 
the composite is dissipated during light emission. However, this fraction is very small, so that no permanent change in the specimen height is detected as a result of this dissipation, and the material can be consequently considered to retain a pure linear elastic behaviour. Nevertheless, the energy is dissipated with delay, because the detrapping of carriers cannot instantaneously occur, and this delay is defined by the retardation function. Additionally, large delays can occur because of carriers trapped in swallow traps, as proposed by Chandra et al..$^{9}$ : it explains the ML emission observed when the stress is removed. It turns out that including a threshold stress in the present model based on the mechanical power (Eq. (1)), does not bring a noticeable improvement to the fit of the experimental data.

In order to validate the model, we have performed two compression tests, using the same protocol of UV irradiation and of ML intensity recording. The stress has been increased up to $50 \mathrm{MPa}$, but with controlled fluctuations of the stress rate. The speed of the crossing head has been programmed to obtain the following loading rates: $3.3 \mathrm{MPa} . \mathrm{s}^{-1}$ up to 36 $\mathrm{MPa}, 4.4 \mathrm{MPa} . \mathrm{s}^{-1}$ up to $42 \mathrm{MPa}$ and then $4.5 \mathrm{MPa}^{-1}{ }^{-1}$ up to $50 \mathrm{MPa}$. At each change of loading rate, the machine decreases its loading rate in a reproducible way (as it can been see on the stress curves on the Figure 3). The fluctuations allow a better determination of the fitting parameters. For the first test (named "1"), when the maximum stress was reached, it was kept for $50 \mathrm{~ms}$ and then supressed. For the other test (named "2"), the stress was kept constant during $20 \mathrm{~s}$, before being rapidly supressed (within $50 \mathrm{~ms}$ ). We have first determined the parameters $\phi, \psi, \tau$ and $\beta$ for test " 1 " by a least square fitting method, and these parameters were found to provide an excellent modeling of the second experiment. These parameters are listed in Table I. According to the value of $\tau$ and $\beta$ (see Table I), the average retardation time, and so the average detrapping time constant under stress, given by the integral of $1-\varphi(t)$, from 0 to $\infty$, is 106 seconds.

The model is able to reproduce the effects of stress rate fluctuations and the ML intensity decay under constant stress. Additionally, when the stress starts to decrease, with a sharp stress rate change, a ML intensity peak is observed, and the model reproduces this peak with an equivalent height. When the stress falls down to 0 , the model also provides a relatively good fit of the ML intensity decay, somewhat faster than the experimental one. A better fit could probably be obtained with a refined description of the detrapping rate (Eq. (3)), accounting for an exponential distribution of traps with energy to the expense of additional parameters. It is important to note that the model predicts the ML intensity changes in all 
these different situations with only 3 parameters $(\psi$ just acts as a conversion factor between a mechanical power and the arbitrary unit of $\left.I_{M L}\right)$.

In conclusion, we have synthesized by melt-quenching method, a translucent glass composite exhibiting mechanoluminescence. Experiments conducted on compression have shown that the EML intensity scales with the mechanical power. An explicit relationship between the stress and the ML intensity is proposed. Based on a single equation, this model provides a smooth fit even for a rather complex loading cycle.

Region Bretagne and the European Research Council (through the ERC Advanced Grant 320506) are gratefully acknowledged for funding and supporting these researches.

\section{REFERENCES}

${ }^{1} \mathrm{~F}$. Bacon, The advancement of learning (Book IV, Oxford, 1605).

${ }^{2} \mathrm{P}$. Jha and B. P. Chandra, "Impulsive excitation of mechanoluminescence in $\mathrm{SrAl}_{2} \mathrm{O}_{4}: \mathrm{Eu}$, Dy phosphors prepared by solid state reaction technique in reduction atmosphere," J. Lumin., 143, $280-287$ (2013).

${ }^{3}$ C.-N. Xu, T. Watanabe, M. Akiyama, and X. Zheng, "Artificial skin to sense mechanical stress by visible light emission," Appl. Phys. Lett., 74, 1236-1238 (1999).

${ }^{4} \mathrm{X} . \mathrm{Fu}, \mathrm{H}$. Zhang, L. Fang, and H. Fu, "Preparation and mechanoluminescent properties of $\mathrm{SrAl}_{2} \mathrm{O}_{4}$ :Eu film grown on silicon substrate using double buffer layers," Thin Solid Films, 540, $41-45$ (2013).

${ }^{5}$ G. J. Yun, M. R. Rahimi, A. H. Gandomi, G.-C. Lim, and J.-S. Choi, "Stress sensing performance using mechanoluminescence of $\mathrm{SrAl}_{2} \mathrm{O}_{4}: \mathrm{Eu}(\mathrm{SAOE})$ and $\mathrm{SrAl}_{2} \mathrm{O}_{4}: \mathrm{Eu}$, Dy (SAOED) under mechanical loadings," Smart Mater. Struct., 22, 055006 (2013).

${ }^{6}$ Y. Cheng, Y. Zhao, Y. Zhang, and X. Cao, "Preparation of $\mathrm{SrAl}_{2} \mathrm{O}_{4}: \mathrm{Eu}^{2+}, \mathrm{Dy}^{3+}$ fibers by electrospinning combined with sol-gel process," J. Colloid Interface Sci., 344, 321 - 326 (2010).

${ }^{7}$ J. S. Kim, Y.-N. Kwon, N. Shin, and K.-S. Sohn, "Visualization of fractures in alumina ceramics by mechanoluminescence," Acta Mater., 53, 4337 - 4343 (2005).

${ }^{8}$ B. P. Chandra, V. K. Chandra, and P. Jha, "Microscopic theory of elasticomechanoluminescent smart materials," Appl. Phys. Lett., 104, 031102 (2014).

${ }^{9}$ V. K. Chandra and B. P. Chandra, "Suitable materials for elastico mechanluminescence- 
based stress sensors," Opt. Mater., 34, 194-200 (2011).

${ }^{10}$ N. A. Atari, "Piezoluminescence phenomenon," Phys. Lett. A, 90, 93 - 96 (1982).

${ }^{11}$ V. K. Chandra, B. P. Chandra, and P. Jha, "Strong luminescence induced by elastic deformation of piezoelectric crystals," Appl. Phys. Lett., 102, 241105 (2013).

${ }^{12}$ M. R. Rahimi, G. J. Yun, and J.-S. Choi, "A predictive mechanoluminescence transduction model for thin-film $\mathrm{SrAl}_{2} \mathrm{O}_{4}: \mathrm{Eu}^{2+}, \mathrm{Dy}^{3+}$ (SAOED) stress sensor," Acta Mater., 77, 200 $211(2014)$.

${ }^{13}$ C.-N. Xu, H. Yamada, X. Wang, and X. G. Zheng, "Strong elasticoluminescence from monoclinic-structure $\mathrm{SrAl}_{2} \mathrm{O}_{4}, "$ Appl. Phys. Lett., 84 (16), 3040-3042 (2004).

${ }^{14}$ M. Akiyama, C.-N. Xu, K. Nonaka, and T. Watanabe, "Intense visible light emission from $\mathrm{Sr}_{3} \mathrm{Al}_{2} \mathrm{O}_{6}: \mathrm{Eu}, \mathrm{Dy}, "$ Appl. Phys. Lett., 73, 3046 (1998).

${ }^{15}$ V. K. Chandra and B. P. Chandra, "Dynamics of the mechanoluminescence induced by elastic deformation of persistent luminescent crystal," J. Lumin., 132, 858-869 (2012).

${ }^{16}$ M. Akiyama, C.-N. Xu, Y. Liu, K. Nonaka, and T. Watanabe, "Influence of Eu, Dy codoped strontium aluminate composition on mechanoluminescence intensity," J. Lumin., 97, 13-18 (2002).

${ }^{17}$ R. S. Lakes, Viscoelastic solids (CRC press, 1998).

${ }^{18}$ J. Kakalios, R. A. Street, and W. B. Zheng, "Stretched-exponential relaxation arising from dispersive diffusion of hydrogen in amorphous silicon," Phys. Rev. Lett., 59, 1037-1040 (1987).

\begin{tabular}{|c|c|}
\hline Parameter & Value \\
\hline \hline$\beta$ & $0.78 \pm 0.01$ \\
\hline$\tau(\mathrm{s})$ & $92 \pm 4$ \\
\hline $\log _{10}\left(\phi\left(\mathrm{J} . \mathrm{m}^{-3}\right)^{-1}\right)$ & $-3.91 \pm 0.01$ \\
\hline $\log _{10}(\psi)$ & $2.51 \pm 0.01$ \\
\hline
\end{tabular}

TABLE I. Parameters used in the model to fit and predict the ML intensity. 


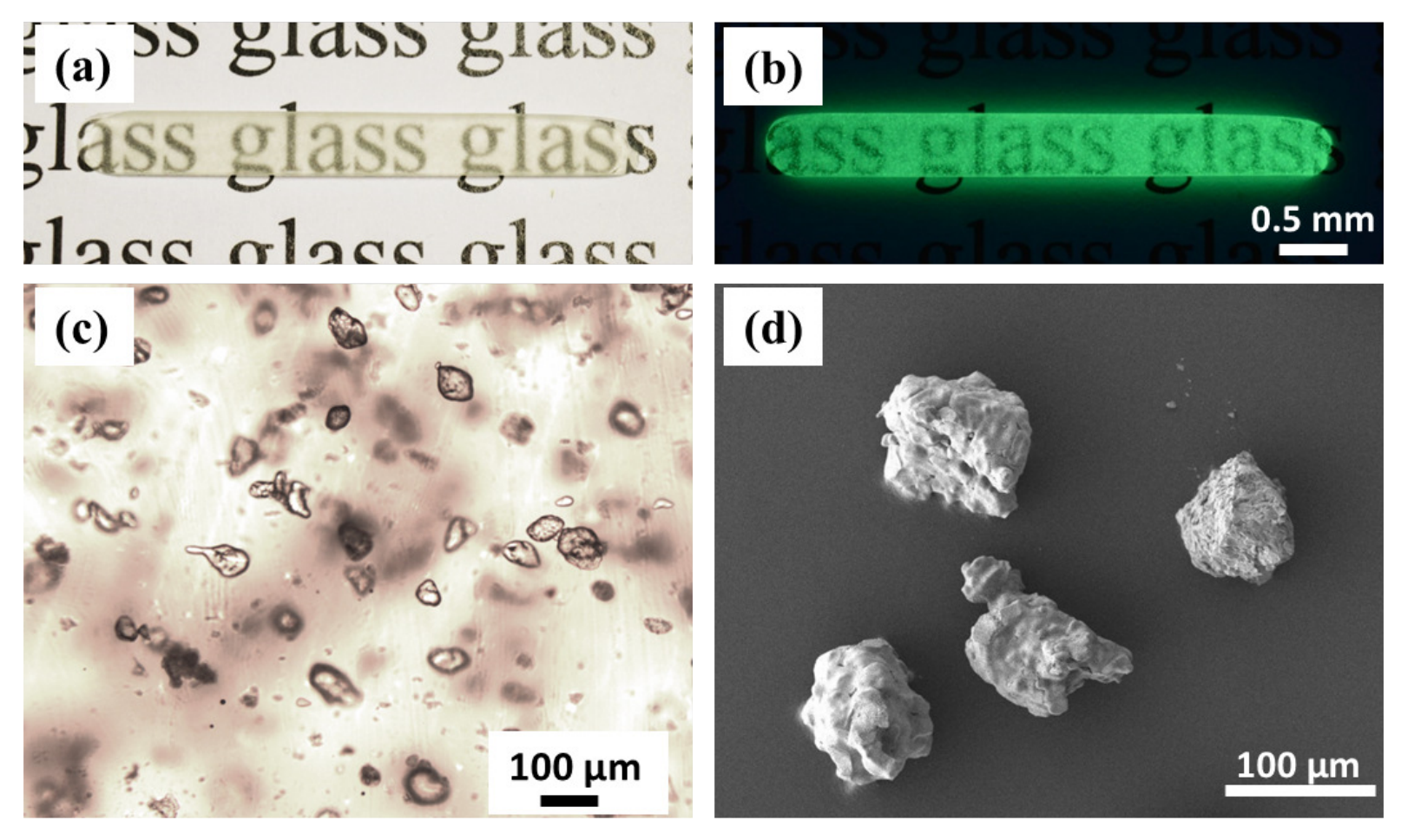

FIG. 1. Images of the composite bulk: (a) under daylight and (b) in the dark just after UV excitation. (c) Image of the SAOED particles dispersed in the glass matrix and (d) particles observed by SEM. 


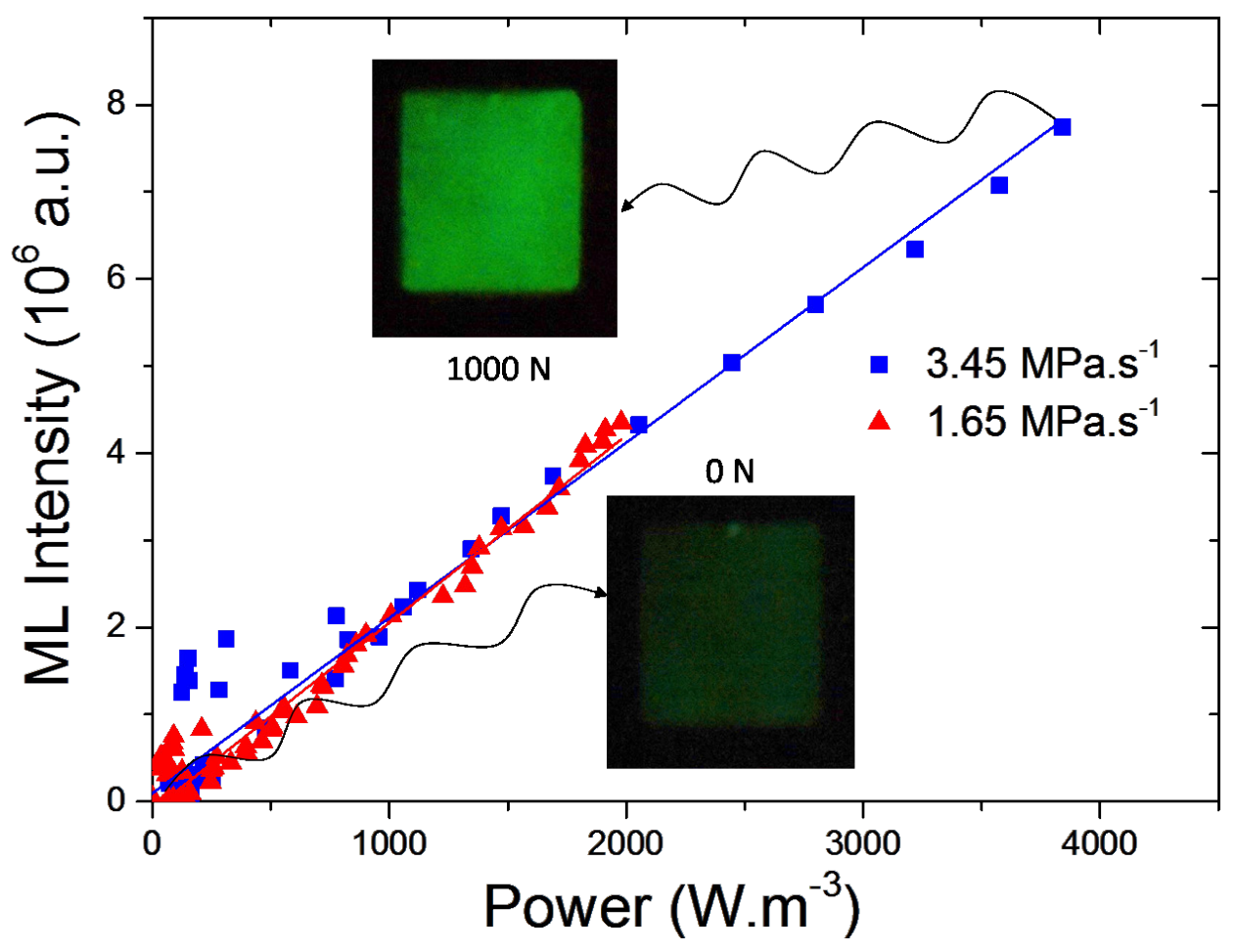

FIG. 2. ML intensity of the composite as a function of the mechanical power. Images of the glass

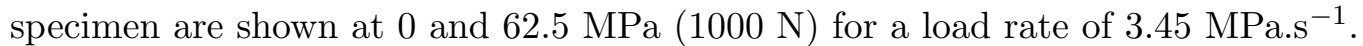




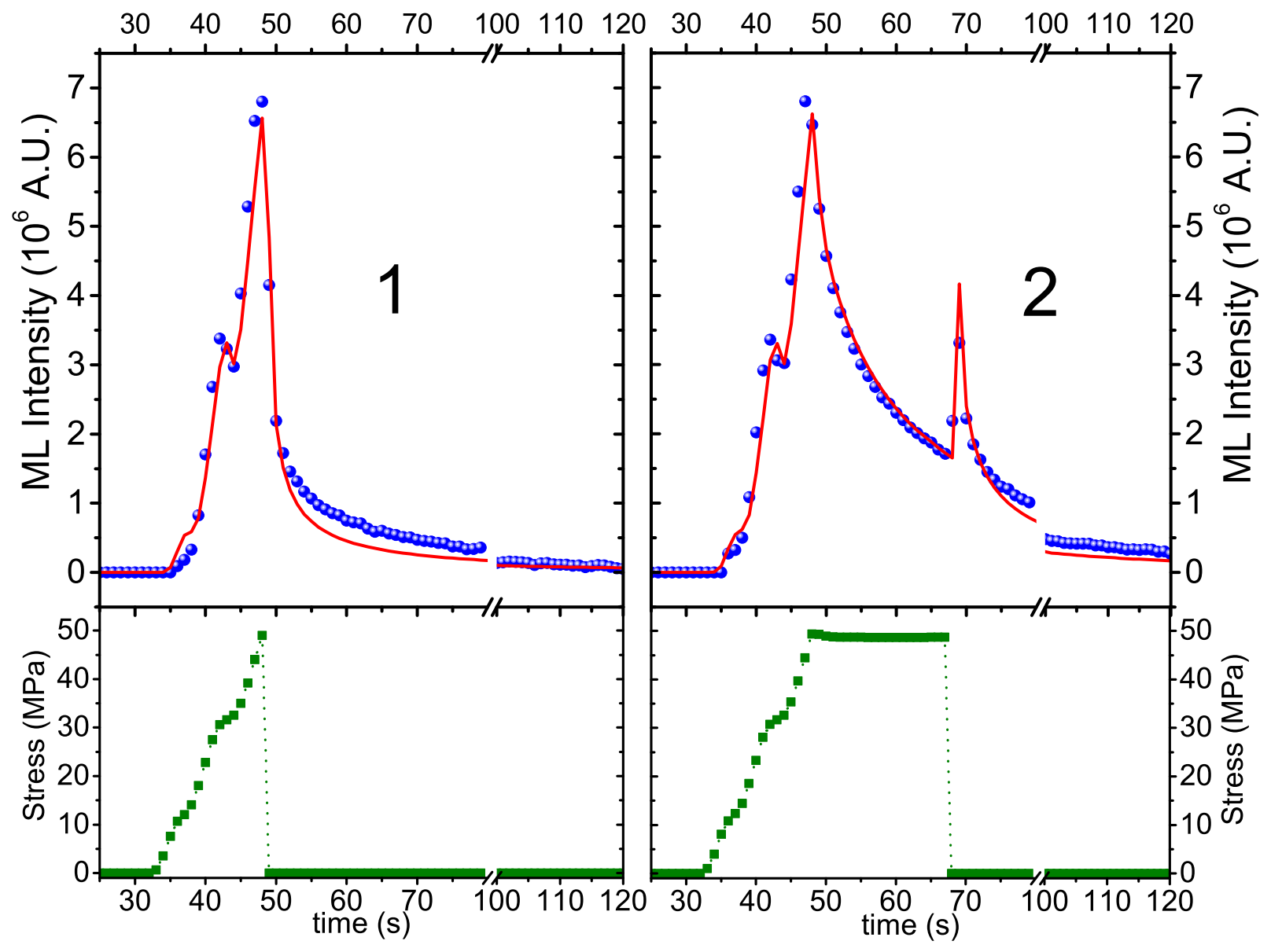

FIG. 3. On the top: ML intensity recorded (blue circles) for two different mechanical loading histories on the glass composite, and their fitting by the model (red lines). On the bottom, the corresponding mechanical loading histories. 